\title{
INCREASED OIL PRODUCTION AND RESERVES FROM IMPROVED COMPLETION TECHNIQUES IN THE BLUEBELL FIELD\# UINTA BASIN\# UTAH
}

Quarterly Technical Report: 01/01/1997 - 03/31/1997

Authors: Craig D. Morgan

Report Issue Date: 05/09/1997

DE-FC22-92BC14953

Utah Geological Survey 1594 W. North Temple

P. O. Box 146100

Salt Lake City, UT 84114-6100 


\section{Objectives}

The objective of this project is to increase oil production and reserves in the Uinta Basin by demonstrating improved completion techniques. Low productivity of Uinta Basin wells is caused by gross production intervals of several thousand feet that contain perforated thief zones, water-bearing zones, and unperforated oil-bearing intervals. Geologic and engineering characterization and computer simulation of the Green River and Wasatch Formations in the Bluebell field will determine reservoir heterogeneities related to fractures and depositional trends. This will be followed by drilling and recompletion of several wells to demonstrate improved completion techniques based on the reservoir characterization. Transfer of the project results will be an ongoing component of the project.

\section{SUMMARY OF TECHNICAL PROGRESS}

\section{Results from the Recompletion of the Michelle Ute 7-1 Well}

\section{Introduction}

The Michelle Ute 7-1 well (section 7, T. 1 S., R. 1 E., USM) was logged, additional beds were perforated, and the lower Wasatch Formation was stimulated with hydrochloric acid during the previous quarter ( $13^{\text {th }}$ Quarterly Technical Progress Report). The plan was to stimulate the well with a three-stage, high pressure $(10,000 \mathrm{psi}[68,950 \mathrm{kPa}])$ acid treatment. But, the tubing leaked and would not hold the high pressure so the acid treatment was applied from one packer location over an interval of 12,899 to $14,450 \mathrm{ft}(3934.2-4026.0 \mathrm{~m})$ at a maximum pressure of $6,500 \mathrm{psi}(44,820 \mathrm{kPa})$. At the end of the previous quarter the operator (Quinex Energy Corporation, Bountiful, Utah) was tripping in the hole with the production packer and tubing to begin swab testing the well.

The well has been producing hydrocarbons (swab tested then placed on pump) at an improved daily rate since the acid treatment. The isotope tracer log that was run after the treatment shows that very few of the perforated beds received acid. The dipole shear anisotrophy $\log$ was not run after the treatment as planned. Therefore a comparison of fracture density before and after the treatment could not be made.

\section{Production}

The Michelle Ute 7-1 well produced an average of 19 barrels of oil per day (BO/D [2.7 $\mathrm{MT} / \mathrm{D}]$ ) prior to the acid treatment (figure 1). The well was shut in on a regular basis as the daily rate dropped below economic limits. After the treatment, the well produced about 40 BO/D (5.6 MT/D) initially, but production is currently declining. The down-hole pump has been replaced several times since the treatment because oil emulsion and fines, which wear out the pump, are still being produced. The increased production is encouraging considering how few beds were actually treated. 


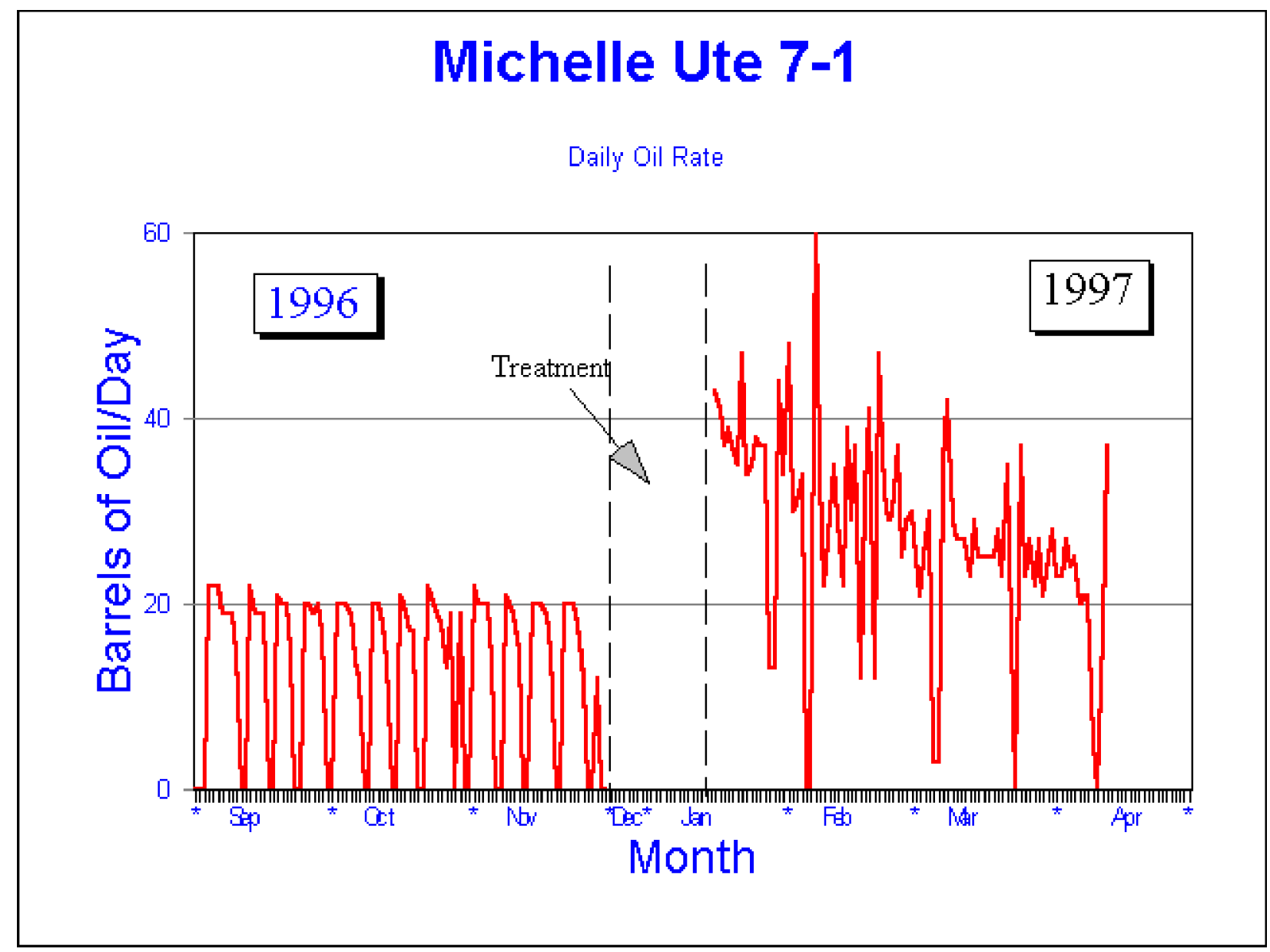

Figure 1. Daily oil production from the Michelle Ute 7-1 well three months before and three months after the acid treatment.

\section{Cased-Hole Logs}

Dipole shear anisotrophy and dual burst thermal decay time (TDT) logs were run before and an isotope tracer log was run after the treatment. The TDT log indicates hydrocarbons in most of the sandstone beds in the logged interval (figures 2 and 3, Log A) as anticipated from analysis of the open hole logs. The TDT log was used to help select beds to be perforated before the treatment. Perforations are shown in the depth column of the TDT log, previous perforations (still open) are on the right, and perforations added with this recompletion are on the left. Some older perforated intervals were re-perforated.

The computer processed log of the dipole shear anisotrophy data (figures 2 and 3, Log B) provides an interpretation of the density of open fractures in the formation. The solid black tracings in the depth column of Log B represent the density of open fractures in the formation; the width of the solid black tracing is proportional to the density of the fracturing. The log shows 
several beds with open fractures $(12,990 ; 13,260 ; 13,280 \mathrm{ft}[3961.9,4044.3,4050.4 \mathrm{~m}]$ figure 2: and 13,$500 ; 13,748 ; 13,846 ; 13,890 \mathrm{ft}[4117.5,4193.1,4223.0,4236.5 \mathrm{~m}]$ figure 3$)$.

The tracer log shows which beds the acid entered by recording the position of encapsulated radioactive isotopes that were added to the acid but remain in the formation after the treatment. The perforations in the upper $500 \mathrm{ft}(152.5 \mathrm{~m})$ of the treated interval received most of the acid (figure 2, $\log \mathrm{C}$ ). Perforations from 13,400 to 13,550 ft (4087-4133 m) received only a minor amount of acid and from $13,550 \mathrm{ft}(4133 \mathrm{~m})$ to total depth, the perforations received no acid (figure $3, \log \mathrm{C}$ ).

\section{Fracture Interpretation}

The dipole shear anisotrophy log was not run after the treatment as planned so it cannot be determined if new fractures were opened by the treatment. Also, the repeatability of the log (do fractures shown on the first log run show on the second run as well?) is an important aspect of determining the reliability of the data. However, comparison of the dipole shear anisotrophy to the tracer log does give credence to the fracture interpretation.

The tracer log shows the acid went above or below the perforations in some places, corresponding to fractures indicated on the dipole shear anisotrophy log. Examples of this can be seen from 13,080 to 13,110 ft (3989.4-3998.6 m) and from 13,240 to 13,250 ft (4038.2-4041.3 $\mathrm{m}$ ) (figure 2). Fractures identified in core and borehole imaging logs throughout the Bluebell field typically are $90 \%$ or more calcite filled. Operators have often speculated that the acid treatments open up these calcite-filled fractures. The most prominent indication of fractures $(12,990 ; 13,280$ $\mathrm{ft}[3961.9,4050.4 \mathrm{~m}]$ figure 2: and 13,846 ft [4223.0 m] figure 3: for example) are in beds that were previously perforated and acidized. The prominent fracture at 13,260 ft (4044.3 m) (figure 2 ) is an exception. Only moderate fracture density is indicated by the dipole shear anisotrophy log in beds that have not been perforated and treated prior to running the $\log (13,500 ; 13,520 ; 13,750$ $\mathrm{ft}$ [4117.5, 4123.6, 4193.8 m] figure 3: for example).

Core and borehole imaging logs from the Bluebell field show that most fractures terminate at bed boundaries. The bed from 12,985 to $12,996 \mathrm{ft}(3960.4-3963.8 \mathrm{~m})$ is separated from the sandstone bed below by a thin (4-ft [1.2-m]) shale break. The upper bed appears to have fractures that terminate downward at the shale break (figure 2, Log B) but the lower bed is not fractured. The tracer $\log$ shows that acid went into both beds but not into the shale break between them (figure 2, $\log C$ ). This indicates that the fractures in the upper bed do terminate at the bed boundary and do not penetrate the shale break.

\section{Future Activity}

The next demonstration will consist of hydro-jetting a 10-ft (3-m) lateral hole in three or more beds in a well in the study area. Each bed will be acidized separately. The economics of treating select individual beds will be compared to the current practice of treating large intervals. Selection of the beds to treat in the next demonstration well will be based on standard geophysical well-log analysis, correlation to neighboring wells, past production logs (temperature and spinner), and cased-hole dipole shear anisotrophy logs. 


\section{Fractured Reservoir Simulations}

Correlations exist between rock types and fracturing tendencies. The data for several cores from the Bluebell field were compiled and used to develope a new technique for incorporating information on fractures in the simulation models. The procedure used in generating field-wide fracture frequency information is as follows:

1. The data on rock types and fracture frequencies are compiled into a lookup table.

2. Indicator simulations (simulations involving discrete variables) are used to generate rock-type distributions in a given domain. The domain could be two- or threedimensional. In this study, a two-dimensional (cross-section) domain was used because of a lack of good quality three-dimensional data.

3. The fracture frequency data from the lookup table are used as "hard" conditioning and the generated rock-type distribution is used as "soft" conditioning in Markov-Bayes conditional simulations to obtain fracturing frequencies in each location of the reservoir.

This Markov-Bayes approach was compared to other traditional approaches such as Gaussian and indicator simulations using fracture frequency data. The newly developed method results in distributions which honor the rock-type/fracture-frequency correlation better than the other traditional approaches. Subsequent flow simulations showed that it is important to represent the fracture information as accurately as possible since fractures significantly impact the production.

\section{Technology Transfer}

The Utah Geological Survey maintains a Bluebell home page on its web site containing the following information: (1) a description of the project, (2) a list of project participants, (3) each of the Quarterly Technical Progress Reports, (4) a description of planned field demonstration work, (5) portions of the First and Second Annual Technical Reports with information on where to obtain complete reports, (6) a reference list of all publications that are a direct result of the project, (7) an extensive selected reference list for the Uinta Basin and lacustrine deposits worldwide, and (8) daily activity reports of the Michelle Ute 7-1 demonstration work. The home page address is http://utstdpwww.state.ut.us/ ugs/bluebell.htm 
Figure 2. Cased-hole logs (12,900-13,400 ft [3921.6-4073.6 m]) from the Michelle Ute 7-1 well. $\log \mathrm{A}$ is the dual burst thermal decay time $\log ; \log \mathrm{B}$ is a portion of the dipole shear anisotrophy $\log$; and $\log \mathrm{C}$ is the multiple isotope tracer $\log$.

Figure 3. Cased-hole $\operatorname{logs}(13,400-13,900 \mathrm{ft}[4073.6-4225.6 \mathrm{~m}])$ from the Michelle Ute 7-1 well. $\log \mathrm{A}$ is the dual burst thermal decay time $\log ; \log \mathrm{B}$ is a portion of the dipole shear anisotrophy $\log$; and $\log \mathrm{C}$ is the multiple isotope tracer $\log$. 


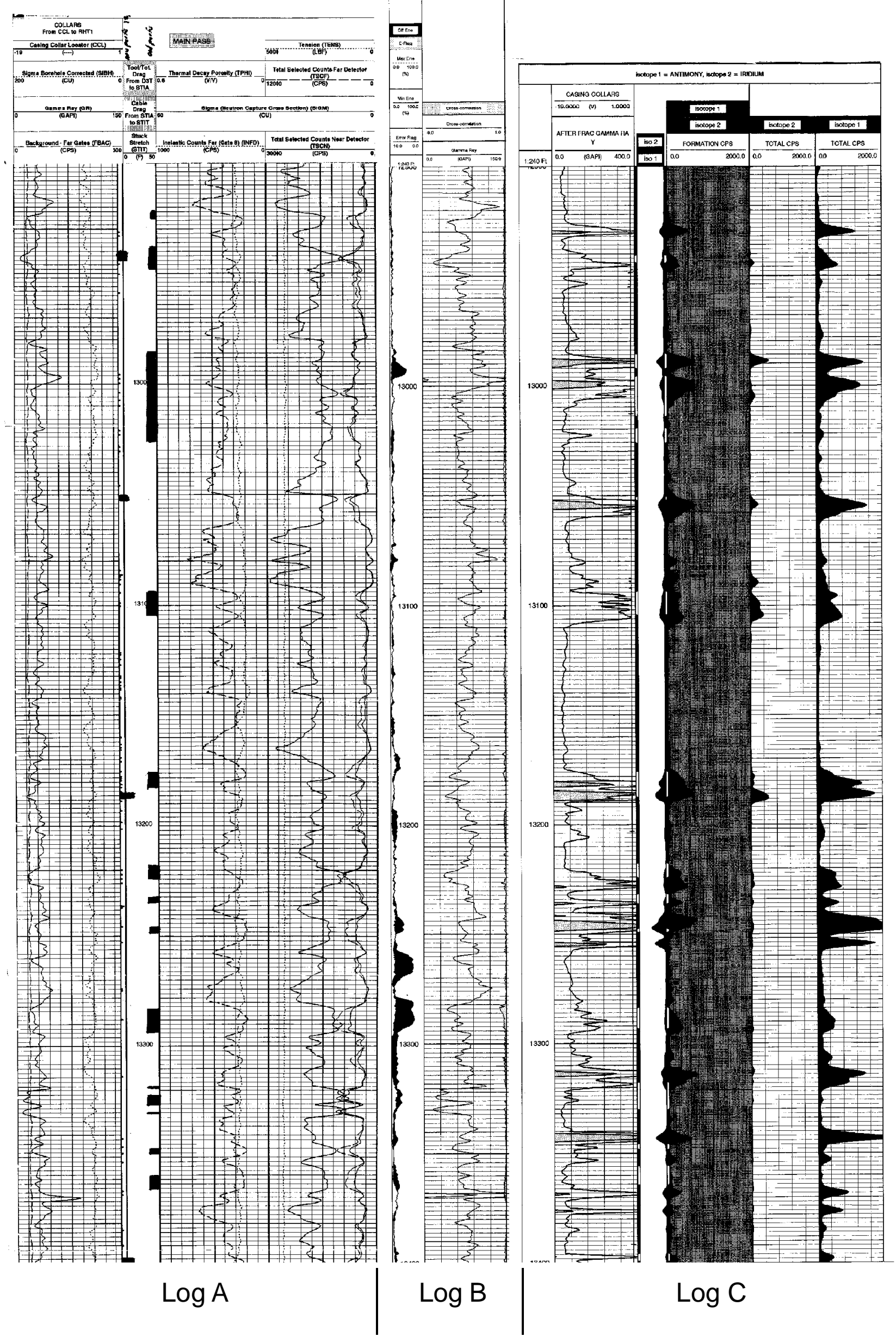




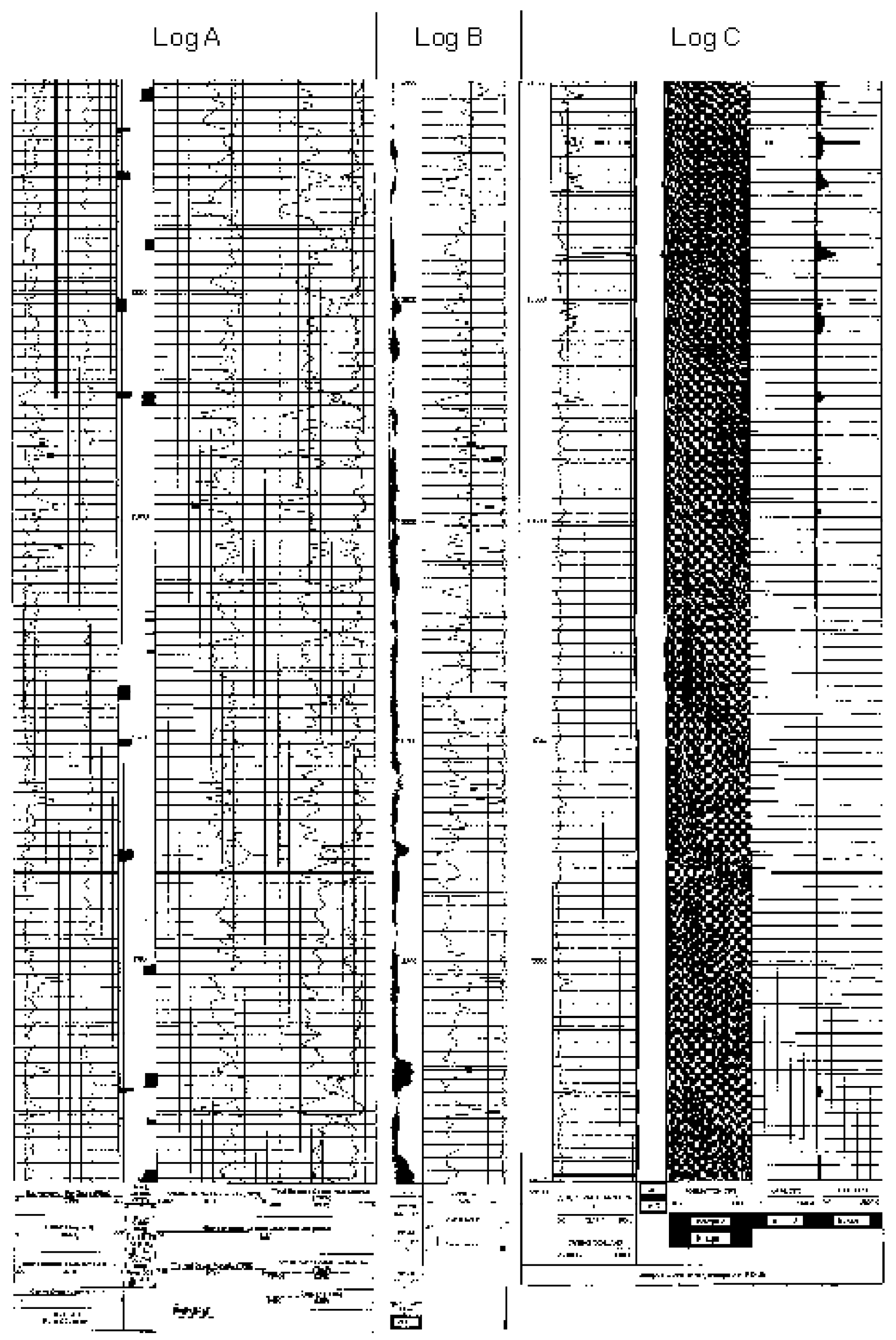

